\title{
Pengaruh Store Layout, Interior Display dan Human terhadap Shopping Orientation
}

\author{
Ainil Mardiah* \\ Program Magister Manajemen, Fakultas Ekonomi. Universitas Andalas \\ J1. Perintis Kemerdekaan No. 77 Jati, Padang 25129, Sumatera Barat, Indonesia \\ a.mardiahainil@gmail.com
}

\section{Susi Evanita}

Fakultas Ekonomi. Universitas Negeri Padang

Jl. Prof. Dr. Hamka, Air Tawar, Padang 25131, Sumatera Barat, Indonesia

susievanita@gmail.com

\section{Whyosi Septrizola}

Fakultas Ekonomi. Universitas Negeri Padang

Jl. Prof. Dr. Hamka, Air Tawar, Padang 25131, Sumatera Barat, Indonesia whyosiseptrizola.ws@gmail.com

Diterima: 26-09-2020 | Disetujui: 07-07-2021 | Dipublikasi: 31-07-2021

\begin{abstract}
(c)
\begin{abstract}
ABSTRAK
Shopping orientation didefinisikan sebagai suatu bentuk ketertarikan yang melekat pada individu dan kemudian memberikan motivasi dalam melakukan pembelian terhadap suatu produk. Shopping orientation memiliki keterikatan dengan hubungan sosial karena hal itu menyangkut dengan bagaimana konsumen merefleksikan suatu keadaan konsumen dalam lingkungan perbelanjaan. Tujuan penelitian ini adalah untuk mengetahui pengaruh store layout, interior display, dan human terhadap shopping orientation di Matahari Basko Grand Mall Padang. Secara umum hasil penelitian ini menunjukkan bahwa: store layout berpengaruh signifikan terhadap shopping orientation di Matahari Basko Grand Mall, interior display berpengaruh signifikan terhadap Shopping Orientation di Matahari Basko Grand Mall. Sedangkan human tidak berpengaruh signifikan terhadap Shopping Orientation di Matahari Basko Grand Mall.
\end{abstract}

Kata Kunci:

Store Atmosphere; Store Layout; Interior Display; Human; Shopping Orientation.

\begin{abstract}
Shopping orientation is defined as a form of interest attached to the individual and then provides motivation in making a purchase of a product. Shopping orientation has an attachment to social relationships because it involves how consumers reflect consumer conditions in the shopping environment. The purpose of this study was to determine the effect of store layout, interior appearance, and people on shopping orientation at Matahari Basko Grand Mall Padang. In general, the results of this study indicate that: store layout has a significant effect on shopping orientation at Matahari Basko Grand Mall, interior appearance has a significant effect on Shopping Orientation at Matahari Basko Grand Mall. Meanwhile, humans have no significant effect on Matahari Basko Grand Mall Shopping Orientation.
\end{abstract}

Keywords:

Store Atmosphere; Store Layout; Interior Display; Human; Shopping Orientatio 


\section{PENDAHULUAN}

Pertumbuhan bisnis ritel modern di Indonesia mengalami kemajuan yang sangat drastis. Hal ini dapat dilihat dari pesatnya pembangunan pusat perbelanjaan dan gerai-gerai baru di seluruh wilayah Indonesia. Pemilik bisnis ritel terutama yang berbasis gerai sangat cekatan dalam menghadapi perubahan. Berbagai macam ide dan inovasi dikembangkan oleh para pemilik ritel untuk memajukan bisnisnya dan menciptakan sesuatu yang berbeda dari yang lain. Ditambah lagi, bisnis ritel ini sangat erat kaitannya dengan persaingan karena, tidak mungkin suatu perusahaan berdiri tanpa adanya perusahaan lain sebagai pesaing dalam bisnis. Persaingan ini merupakan salah satu faktor yang mendorong perusahaan memperbaiki produktivitasnya dan melakukan inovasi. Dalam kondisi seperti ini perusahaan dituntut harus bertahan hidup bahkan terus berkembang. Khususnnya di Kota Padang persaingan bisnis ritel juga mengalami perkembangan yang pesat. Seperti minimarket, supermarket dan hypermarket.

Di Kota Padang, bisnis ritel modern berskala nasional masih menjadi pilihan utama masyarakat untuk berekreasi. Hal ini dapat dilihat pada libur akhir pekan sabtu dan minggu, dimana lokasi-lokasi yang terdapat pusat perbelanjaan tersebut mengalami kepadatan lalu lintas, macet dan terdapat banyak kerumunan orang yang berlalu lalang di dalam maupun di luar pusat perbelanjaan. Salah satunya adalah Matahari Basko Grand Mall. Hal ini sesuai dengan apa yang disampaikan oleh beberapa peneliti lainnya yang menyatakan bahwa konsumen yang memiliki orientasi belanja sebagai kebutuhan untuk berekreasi memiliki kecenderungan untuk berbelanja dipusat perbelanjaan yang bergengsi, dengan aneka ragam produk yang menarik dan berkualitas dengan menyuguhkan suasana belanja yang nyaman dan menyenangkan serta menyediakan fasilitas yang lengkap.

Perubahan dari perilaku konsumen juga membuat perusahaan harus merubah orientasinya. Saat ini bisnis tidak lagi berorientasi pada keuntungan atau laba melainkan berorientasi pada pelanggan. Menurut Kurniawan \& Yohanes (2013) pemasaran yang efektif digunakan saat ini yaitu yang berorientasi pada konsumen, dengan mengetahui apa yang diinginkan dan dibutuhkan oleh konsumen akan memudahkan pemilik bisnis untuk mendapatkan target pasarnya sehingga berujung pada tindakan pembelian konsumen. Harapan dan ekspektasi pelanggan harus mampu dipenuhi oleh pemilik. Membuat konsumen menjadi tertarik untuk mengunjungi sebuah toko bukan hanya dengan menyediakan produk yang mereka butuhkan tetapi juga harus mampu memenuhi kebutuhan emosional konsumen guna menumbuhkan shopping orientation pelanggan pada toko tersebut. Karena beberapa pelanggan melakukan kunjungan ke sebuah toko memiliki motif yang berbeda. Terdapat berbagai macam faktor yang dapat memberikan stimulus dalam membangun shopping orientation pada pelanggan, dalam hal ini penulis memilih pendesainan store atmosphere atau suasana toko. Pemilik usaha harus menyediakan store atmosphere yang mampu memberikan stimulus kepada pelanggan sehingga mereka tertarik untuk datang mengunjungi toko dan melakukan pembelian. Memainkan respon emosi pelanggan ketika berada di dalam toko merupakan salah satu hal yang harus dilakukan oleh pelaku bisnis. Kenyataannya pelanggan akan menjadikan pengalaman belanja 
sebelumnya sebagai tolak ukur untuk melakukan kunjungan ataupun pembelian di sebuah toko. Respon emosi yang baik yang didapatkan oleh konsumen akan membangun shopping orientation pada pelanggan.

Matahari Basko Grand Mall memiliki desain store atmosphere yang unik dan menarik. Pencahayaan lampu yang tertata dengan baik, sangat menarik mata ketika pelanggan menatap kebagian dalam toko, konsumen disuguhkan dengan kemilau cahaya lampu dengan pencahayaan yang tepat dan bagus. Selain itu juga terdapat human dalam hal ini karyawan toko yang berpakaian rapi, bersih dan ramah yang menyambut kedatangan para konsumen dan pelanggannya. Serta terlihat pemilihan desain pada dinding toko yang nampak serasi dengan produk-produk yang disediakan. Suasana yang seperti ini merupakan salah satu hal yang mendorong terjadinya pembelian, pengalaman belanja yang menyenangkan dan menjadi referensi untuk melakukan kunjungan selanjutnya. Ketika store atmosphere telah memberikan stimulus yang baik pada konsumen maka dengan sendirinya orientasi belanja akan tertanam di benak konsumen, dalam hal ini tertuju pada Matahari Basko Grand Mall.

Berdasarkan pada fenomena-fenomena yang terjadi di atas, maka dapat penulis pahami bahwa elemen-elemen store atmosphere merupakan salah satu unsur terpenting dalam membangun terhadap shopping orientation pada pelanggan di Matahari Basko Grand Mall Padang. Untuk mengetahui seberapa jauh pengaruh elemen-elemen store atmosphere terhadap shopping orientation maka diperlukan kajian yang lebih komprehensif. Dalam penelitian ini elemen-elemen store atmosphere yang akan diteliti adalah store layout, interior display dan human. Adapun rumusan masalah dalam penelitian ini yaitu sejauh mana store layout, interior display dan human berpengaruh positif dan signifikan terhadap shopping orientation di Matahari Basko Grand Mall Padang. Penelitian ini bertujuan untuk mengetahui hubungan store layout, interior display dan human berpengaruh positif dan signifikan terhadap shopping orientation di Matahari Basko Grand Mall Padang.

\section{Shopping Orientation}

Shopping orientation didefinisikan sebagai suatu bentuk ketertarikan yang melekat pada individu dan kemudian memberikan motivasi dalam melakukan pembelian terhadap suatu produk. Menurut Solomon (2011) shopping orientation atau orientasi belanja merupakan bentuk ketertarikan seseorang yang memotivasinya untuk melakukan pembelian. Shopping orientation merupakan suatu daya tarik yang mampu untuk mengalihkan fokus konsumen ketika membeli produk tertentu. Shopping orientation memiliki keterikatan dengan hubungan sosial karena hal itu menyangkut dengan bagaimana konsumen merefleksikan suatu keadaan konsumen dalam lingkungan perbelanjaan. Adapun indikator dari shopping orientation adalah sebagai berikut:

1. Shopping orientation secara spontan. Thamizhvanan (2013) menyatakan bahwa hal ini merupakan suatu kebiasaan belanja yang dilakukan tanpa perencanaan atau berlangsung 
begitu saja yang secara objektif memiliki hubungan dengan keinginan emosional seorang pembeli.

2. Orientasi pada merek. Thamizhvanan, (2013) sejauh mana merk mendapatkan tempat atau posisi yang menarik dalam pandangan seorang konsumen, sehingga merk tersebut memiliki perbedaan dengan yang lainnya. Menentukan pilihan pada suatu merek biasanya sangat identik dengan status sosial seorang pembeli.

3. Orientasi pada kualitas. Kualitas merupakan pertimbangan yang paling utama bagi sebagian konsumen. Pembeli memiliki harapan yang besar pada produk-produk yang berkualitas.

4. Orientasi pada kesenangan. Orientasi ini didapatkan ketika konsumen menemukan kepuasaan saat melakukan aktivitas belanja. Kesenangan yang ingin diperoleh ini merupakan wujud dari pelarian shopping enjoyment atau kesenangan membeli diartikan sebagai kepuasan berbelanja yang diperoleh dari proses belanja. Kesenangan membeli didefinisikan menjadi tiga jenis konstruk, yaitu: pelarian, kesenangan saat membeli dan gairah yang ditimbulkan pada saat melakukan pembelian.

5. Orientasi pada kenyamanan saat melakukan pembelian ini terjadi ketika yang menjadi motif untuk berbelanja tersebut adalah melakukan penghematan waktu.

\section{Store Layout}

Store layout merupakan elemen yang sangat penting yang harus dimiliki oleh sebuah toko. Melalui penataan store layout yang yang baik dan tertata dengan benar maka hal tersebut akan memberikan kenyamanan kepada konsumen. Kesan yang didapatkan ketika melakukan aktivitas belanja akan membentuk orientasi konsumen untuk melakukan pembelian selanjutnya. Menurut Berman \& Evans (2014) store layout merupakan penataan pada sebuah toko yang dilakukan melalui perencanaan yang terdiri dari menata ruang penempatan, mengkategorikan beraneka ragam produk yang akan ditawarkan, mengatur jalan/lalu lintas (ruang gerak) konsumen, mengatur lebar ruangan yang dibutuhkan, melakukan pemetaan ruang dan menyusun produk berdasarkan pada spesifikasinya.

Ketika seorang peritel mampu untuk menyediakan store layout yang benar maka peritel tersebut akan mendapatkan feedback berupa perilaku konsumen sesuai dengan yang diharapkan. Store layout yang memiliki kemampuan untuk mengundang konsumen untuk datang ke toko ataupun membuat konsumen menjauhi toko yakni kesan ketika konsumen pertama kali memasuki toko dan memperhatikan bagian dalam toko melalui pintu utama ataupun jendela toko. Pengelolaan store layout yang tepat akan membuat konsumen untuk datang ataupun berkunjung kembali ke toko untuk melakukan aktivitas belanja yang lebih lama karena konsumen merasa betah untuk berlama-lama berada di dalam toko tersebut serta melakukan belanja dengan nominal uang yang lebih banyak. Oleh karena itu, peritel yang harus melakukan pengelolaan dan penataan ruang toko (store layout) dengan tepat dan benar agar mampu untuk memenuhi tujuan dan kebutuhan konsumen. Keberhasilan store layout dalam membangun kenyamanan berbelanja akan meningkatkan gairah belanja konsumen untuk 
melakukan pembelian dengan biaya yang lebih besar. Store layout dapat dikategorikan baik apabila memenuhi indikator di bawah ini:

1. Pengalokasian ruangan lantai yang terdiri dari:

a. Ruang penjualan yang yang dipergunakan sebagai tempat berkomunikasinya antara kasir dan pembeli, sebagai tempat untuk pemajangan merchandise, demonstrasi dan berbagai kegiatan lainnya.

b. Ruang Merchandise yang diperuntukan sebagai tempat untuk melakukan penyimpanan barang-barang yang belum dipajang.

c. Ruang karyawan yang dapat dipergunakan sebagai tempat berkumpulnya karyawan seperti tempat untuk beristirahat, berganti pakaian dan makan siang.

d. Ruang konsumen yang akan memberikan kontribusi terhadap suasana hari pengunjung atau konsumen toko. Ruang ini biasara seperti lounge, kursi untuk duduk, ruang ganti, rest room, lokasi parkir ataupun space lalu lintas berupa Lorong yang luas.

2. Mengklasifikasikan produk yang ditawarkan oleh toko berdasarkan pada keserasian dan pengelompokan produk sesuai dengan spesifikasinya. Yang terdiri dari:

a. Berdasarkan fungsi,

b. Berdasarkan pada motivasi berbelanja konsumen,

c. Berdasarkan pada segemen pasar yang dituju, dan

d. Berdasarkan pada storability.

3. Pengelolaan sirkulasi jalan/pola lalu lintas belanja konsumen yang biasanya berupa pengaturan gang/lorong yang menyediakan sedikit korner yang mampu memberikan kesan nyaman kepada konsumen ketika mengelilingi toko untuk menemukan produk yang dibutuhkannya (Levy \& Weitz, 2012).

4. Menentukan kebutuhan ruang toko yaitu berupa luas lantai yang diperlukan berdasarkan pada kategori yang telah ditentukan.

5. Melakukan pemetaan pada lokasi ruang di dalam toko yang ditujukan untuk melakukan penataan pada lantai, tempat dimana produk akan diletakkan dan layout seperti apa yang akan digunakan pada setiap lantai.

6. Penyusunan berdasarkan pada spesifikasi produk yang berdasarkan pada kategori ukuran, warna, fungsi dan harga barang yang sesuai dengan kebutuhan konsumen.

H1: Store layout berpengaruh positif dan signifikan terhadap shopping orientation.

\section{Interior Display}

Pemilihan interior display akan sangat mempengaruhi suasana toko hal ini dikarenakan interior display memberikan efek nyaman dan menyenangkan kepada pelanggan saat mereka berada di dalam toko. Interior display juga dapat memberikan kemudahan kepada konsumen untuk mencari informasi mengenai produk dan barang. Sedangkan menurut Berman \& Evans (2014) setiap bagian 
dari elemen interior display harus menyediakan informasi yang berguna bagi pembeli, mampu memberikan atmosfer yang menciptakan keindahan toko agar terkesan menarik yang bertujuan untuk mengarahkan konsumen untuk melihat serta memutuskan untuk melakukan pembelian terhadap produk yang disediakan oleh toko. Tujuan terpenting dari interior display yaitu untuk meningkatkan penjualan produk dan menghasilkan laba. Interior display yang baik memiliki indikator sebagai berikut:

1. Pengaturan tema. Tampilan harus disesuaikan dengan tema seperti hari-hari besar seperti hari kemerdekaan hari raya ataupun hari valentine. Display dan hiasan dinding lainnya harus serasi untuk menampilkan pajangan produk yang disesuaikan dengan musim melalui cara yang special.

2. Tampilan ensemble, seperti patung/mannequin yang harus didandani serasi dengan menggunakan kombinasi yang senada agar tampil modis dan stylish dan menyediakan barangbarang terkait di area yang saling berdekatan satu sama lain.

3. Tampilan rak yang digunakan untuk menyusun, menggantung dan memajang barang-barang agar tersusun rapi dan menarik sehingga terdapat keteraturan barang-barang yang indah dipandang.

4. Tampilan case digunakan untuk memajang/memamerkan barang-barang dengan ukuran yang lebih besar dan memiliki bobot yang berat sehingga tidak bisa dipajang menggunakan rak.

5. Tampilan cut case yang membuat barang yang dipajang memiliki harga yang relatif murah dan dapat mengurangi biaya display yang biasanya lebih mahal dan menggunakan kemasan asli dari produk tersebut.

6. Tampilan dump bin yang berfungsi sebagai tempat untuk meletakkan barang-barang yang sedang dipromosikan (diskon) dan penggunaan dumb bin ini juga dapat memberikan kesan harga yang lebih murah.

Display yang menggunakan konsep yang unik dan menarik akan menjadi daya tarik tersendiri bagi konsumen dan akan memunculkan perasaan senang ketika melihat maupun ketika mencoba suatu produk. Ketika konsumen telah memutuskan untuk melakukan pembelian maka stimuli yang dimiliki oleh interior display telah tercapai. Stimuli inilah yang berfungsi untuk membentuk shopping orientation pada konsumen.

$\mathrm{H}$ 2: Interior display berpengaruh positif dan signifikan terhadap shopping orientation.

\section{Human}

Human merupakan unsur yang berperan sangat penting untuk operasional sebuah toko. Menurut Turley \& Milliman dalam Andreani et al., (2013) berpendapat bahwa human merupakan keterlibatan dari setiap orang yang berada dalam sebuah toko. Gunawan, \& Mohamad (2016) menyebutkan bahwa human harus memberikan pengaruh yang diperoleh dari konsumen dan pelayanan karyawan juga harus memberikan pengaruh yang positif. Dengan demikian human harus 
memiliki keterampilan untuk menyampaikan informasi secara detail dan membangun personalitas yang menyenangkan dan menarik perhatian konsumen agar konsumen dapat memberikan nilai yang positif terhadap produk yang ditawarkan oleh toko. Hal ini guna untuk menciptakan shopping orientation pada toko tersebut.

Menurut Ly (2011) faktor-faktor sosial dalam sebuah toko seperti banyaknya jumlah orang yang terdapat di dalamnya, keberadaan dari manajer, dan karyawan toko sangat mempengaruhi kenyamanan dan kesenangan konsumen serta akan berpengaruh dalam membangun shopping orientation yang positif pada toko.

Beberapa konsumen tidak menyukai keramaian dan hal ini juga disampaikan oleh Turley \& Milliman dalam Andreani et al., (2013) bahwa keramaian yang terjadi di dalam toko memberikan dampak modulasi yang negatif pada pelanggan sehingga pelanggan merasa terganggu dan sangat tidak menyukai hal tersebut. Oleh karena itu perusahaan dapat melakukan strategi adaptasi pada konsumen sehingga mereka tetap nyaman berbelanja meskipun toko dalam keadaan ramai pengunjung. Ketika konsumen memiliki pengalaman berbelanja yang buruk maka akan sangat berpengaruh pada shopping orientation mereka.

Setiap pelanggan memiliki orientasi yang berbeda dalam berbelanja, ada yang hanya ingin membeli produk untuk memenuhi keinginannya ada juga yang bertujuan datang ke sebuah toko untuk menghilangkan stress ataupun bersenang-senang. Untuk memenuhi hal tersebut maka toko harus memenuhi indikator human sebagai berikut:

1. Karakteristik dari karyawan. Toko sangat diharapkan mampu untuk membangun karakter karyawan yang ramah, terampil dan tekun sehingga memberikan keuntungan kepada toko tersebut, baik untuk melayani konsumen maupun menampilkan pajangan produk yang menarik dan memiliki nilai estetika yang tinggi.

2. Seragam karyawan yang terstandarisasi akan membangun image toko pada pelanggannya.

3. Kerumunan/keramaian orang-orang yang berada di dalam toko harus dapat dikelola dan dikendalikan sehingga kenyaman saat konsumen berbelanja tetap terjaga.

4. Karakteristik konsumen yang beragam membuat karyawan harus cekatan dalam memberikan pelayanan yang baik kepada konsumen.

5. Toko harus mampu menjaga privacy (keleluasaan pribadi) konsumen.

Isyarat sosial dalam sebuah toko akan memancing semangat dan gairah untuk berbelanja (Baker \& Wakefield, 2012). Menjaga emosi konsumen saat berada di dalam toko harus sangat diperhatikan oleh peritel karena faktor emosi tersebutlah yang akan membangun kesenangan ketika konsumen berada di dalam toko untuk berbelanja. Ketika seseorang merasa senang berbelanja pada suatu store maka hal tersebut sangat mempengaruhi customer shopping orientation untuk melakukan pembelian berikutnya.

H3: Human berpengaruh positif dan signifikan terhadap shopping orientation. 


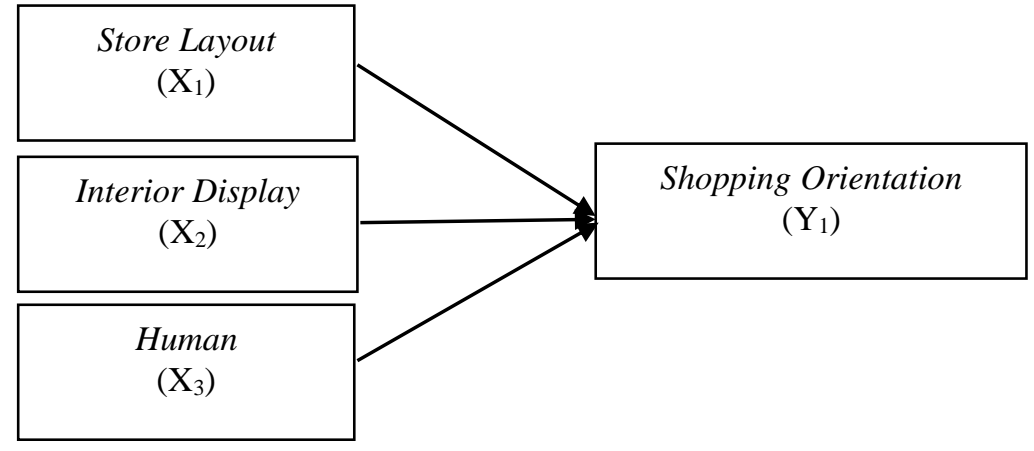

Gambar 1. Kerangka Konseptual

\section{METODE RISET}

\section{Metode Penelitian}

Jenis penelitian yang dikembangkan dalam penelitian ini adalah studi kuantitatif. Menurut Sugiyono (2018) penelitian kuantitatif merupakan suatu metode penelitian yang berdasarkan pada filsafat positivisme, yang dapat digunakan dalam meneliti populasi maupun sampel tertentu, dengan tujuan untuk menguji hipotesis yang telah ditentukan dalam suatu penelitian. Data penelitian diperoleh melalui survei kuesioner.

\section{Definisi Operasional}

Tabel 1. Definisi Operasional Variabel

\begin{tabular}{|c|c|}
\hline Variabel & Indikator \\
\hline $\begin{array}{l}\text { Shopping Orientation }(\mathrm{Y}) \\
\text { Menurut Solomon }(2011) \text { shopping orientation atau orientasi belanja } \\
\text { merupakan bentuk ketertarikan seseorang yang memotivasinya untuk } \\
\text { melakukan pembelian. }\end{array}$ & $\begin{array}{l}\text { Shopping orientation secara spontan } \\
\text { Orientasi merek } \\
\text { Orientasi kualitas } \\
\text { Orientasi kesenangan membeli }\end{array}$ \\
\hline $\begin{array}{l}\text { Store layout }\left(\mathrm{X}_{1}\right) \\
\text { Menurut Berman \& Evans (2014) store layout merupakan penataan } \\
\text { pada sebuah toko yang dilakukan melalui perencanaan yang terdiri } \\
\text { dari menata ruang penempatan, mengkategorikan beraneka ragam } \\
\text { produk yang akan ditawarkan, mengatur jalan/lalu lintas (ruang } \\
\text { gerak) konsumen, mengatur lebar ruangan yang dibutuhkan, } \\
\text { melakukan pemetaan ruang dan menyusun produk berdasarkan pada } \\
\text { spesifikasinya. } \\
\text { Interior Display }\left(\mathrm{X}_{2}\right)\end{array}$ & $\begin{array}{l}\text { Pengalokasian ruangan } \\
\text { Pengelolaan sirkulasi jalan } \\
\text { Klasifikasi produk yang ditawarkan } \\
\text { Lokasi kerja karyawan }\end{array}$ \\
\hline $\begin{array}{l}\text { Menurut Berman \& Evans (2014) setiap bagian dari elemen interior } \\
\text { display harus menyediakan informasi yang berguna bagi pembeli, } \\
\text { mampu memberikan atmosfer yang menciptakan keindahan toko agar } \\
\text { terkesan menarik yang bertujuan untuk mengarahkan konsumen } \\
\text { untuk melihat serta memutuskan untuk melakukan pembelian } \\
\text { terhadap produk yang disediakan oleh toko. } \\
\text { Human }\left(\mathrm{X}_{3}\right)\end{array}$ & $\begin{array}{l}\text { Penyatuan tampilan } \\
\text { Pengaturan tema } \\
\text { Tampilan harga } \\
\text { Hiasan dinding }\end{array}$ \\
\hline $\begin{array}{l}\text { Menurut Turley \& Milliman dalam Andreani et al., (2013) } \\
\text { berpendapat bahwa human merupakan keterlibatan dari setiap orang } \\
\text { yang berada dalam sebuah toko. }\end{array}$ & $\begin{array}{l}\text { Karakteristik karyawan } \\
\text { Seragam karyawan } \\
\text { Keramaian/kerumunan } \\
\text { Karakteristik pelanggan }\end{array}$ \\
\hline
\end{tabular}

Sumber: Hasil Olah Data Penulis 
Menurut Sekaran \& Bougie (2016) variabel dependen (Y) adalah variabel utama dalam penelitian. Dalam penelitian ini yang menjadi variabel dependen (Y) yaitu shopping orientation. Sedangkan variabel independen (X) menurut Sekaran \& Bougie (2016) yaitu variabel yang mempengaruhi yang mempengaruhi variabel dependen $(\mathrm{Y})$ baik positif ataupun negatif. Dalam penelitian ini yang menjadi variabel independen $(\mathrm{X})$ yaitu: $\left(\mathrm{X}_{1}\right)$ store layout, $\left(\mathrm{X}_{2}\right)$ interior display, dan $\left(\mathrm{X}_{3}\right)$ human. Definisi operasional variabel dapat dilihat pada tabel 1.

\section{Populasi dan Sampel}

Menurut Sugiyono (2018) populasi merupakan wilayah secara umum, baik itu objek ataupun wilayah yang memenuhi karakteristik dan kualitas yang telah ditentukan oleh peneliti untuk dipelajari dan kemudian disimpulkan. Populasi dalam penelitian ini adalah seluruh pelanggan Matahari Basko Grand Mall selama tahun 2018. Setelah populasi penelitian ditentukan maka langkah selanjutnya yaitu menentukan sampel penelitian.

Menurut Sugiyono (2018) sampel merupakan bagian kecil dari jumlah dan karakteristik yang dimiliki oleh populasi. Sedangkan sampel yang ditetapkan dalam penelitian ini adalah pelanggan Matahari Basko Grand Mall tahun 2018 yang berdomisili di Kota Padang.

\section{HASIL PENELITIAN DAN PEMBAHASAN}

\section{Uji Validitas dan Reliabilitas}

Uji validitas item pernyataan penelitian dapat dilihat pada tabel 3. Berdasarkan perhitungan uji validitas apabila $r_{\text {hitung }} \geq r_{\text {tabel }}$ yaitu 0,3640 maka pernyataan dikatakan valid. Pada tabel 3 dari 37 item pernyataan yang ada, item ID4 pada variabel interior display $\left(\mathrm{X}_{2}\right)$ tidak valid karena karena nilai $\mathrm{r}_{\text {hitung }}<\mathrm{r}_{\text {tabel }}$ yaitu 0,3640 maka item ID4 dikeluarkan dari pernyataan penelitian.

Tabel 2. Uji Reliabilitas

\begin{tabular}{lcc}
\hline \multicolumn{1}{c}{ Variabel } & Nilai Cronbach Alpha & Ket \\
\hline Shopping Orientation $(\mathrm{Y})$ & 0,912 & Reliabel \\
Store Layout $\left(\mathrm{X}_{1}\right)$ & 0,935 & Reliabel \\
Interior Display $\left(\mathrm{X}_{2}\right)$ & 0,916 & Reliabel \\
Human $\left(\mathrm{X}_{3}\right)$ & 0,829 & Reliabel \\
\hline \multicolumn{2}{c}{ Sumber: Hasil Olah Data Penulis }
\end{tabular}

Uji reliabilitas dapat dilihat pada tabel 3. Hasil pengujian ini menunjukkan bahwa tiap variabel dalam penelitian ini reliabel. Karena nilai Cronbach Alpha yang diperoleh masing-masing variabel $\geq 0,8$. 
Tabel 2. Uji Validitas

\begin{tabular}{|c|c|c|c|}
\hline Variabel & Item & R Hitung & Ket \\
\hline \multirow[t]{10}{*}{ Shopping Orientation (Y) } & SO1 & 0,791 & Valid \\
\hline & $\mathrm{SO} 2$ & 0,698 & Valid \\
\hline & $\mathrm{SO} 3$ & 0,808 & Valid \\
\hline & $\mathrm{SO} 4$ & 0,772 & Valid \\
\hline & $\mathrm{SO} 5$ & 0,820 & Valid \\
\hline & SO6 & 0,739 & Valid \\
\hline & SO7 & 0,723 & Valid \\
\hline & $\mathrm{SO} 8$ & 0,813 & Valid \\
\hline & SO9 & 0,808 & Valid \\
\hline & SO10 & 0,796 & Valid \\
\hline \multirow[t]{11}{*}{ Store Layout (X1) } & SL1 & 0,837 & Valid \\
\hline & SL2 & 0,697 & Valid \\
\hline & SL3 & 0,673 & Valid \\
\hline & SL4 & 0,825 & Valid \\
\hline & SL5 & 0,845 & Valid \\
\hline & SL6 & 0,815 & Valid \\
\hline & SL7 & 0,768 & Valid \\
\hline & SL8 & 0,808 & Valid \\
\hline & SL9 & 0,796 & Valid \\
\hline & SL10 & 0,837 & Valid \\
\hline & SL11 & 0,697 & Valid \\
\hline \multirow[t]{8}{*}{ Interior Display (X2) } & ID1 & 0,678 & Valid \\
\hline & ID2 & 0,820 & Valid \\
\hline & ID3 & 0,739 & Valid \\
\hline & ID4 & 0,358 & Tidak Valid \\
\hline & ID5 & 0,739 & Valid \\
\hline & ID6 & 0,723 & Valid \\
\hline & ID7 & 0,813 & Valid \\
\hline & ID8 & 0,808 & Valid \\
\hline \multirow[t]{8}{*}{ Human (X3) } & H1 & 0,796 & Valid \\
\hline & $\mathrm{H} 2$ & 0,837 & Valid \\
\hline & H3 & 0,697 & Valid \\
\hline & $\mathrm{H} 4$ & 0,673 & Valid \\
\hline & H5 & 0,825 & Valid \\
\hline & H6 & 0,845 & Valid \\
\hline & $\mathrm{H} 7$ & 0,815 & Valid \\
\hline & H8 & 0,791 & Valid \\
\hline
\end{tabular}

Sumber: Hasil Olah Data Penulis

\section{Uji Regresi}

Dari tabel 4 di atas, persamaan regresi berganda dapat dirumuskan sebagai berikut:

$$
Y=9,871+0,365 X_{1}+0,221 X_{2}+0,152 X_{3}+e
$$

Berdasarkan pada persamaan regresi tersebut, maka dapat diinterpretasikan: 
Mardiah, A., Evanita, S., \& Septizola, W. (2021). Pengaruh Store Layout, Interior Display ....

1. Besaran konstanta yang diperoleh sebesar 9,871 hal ini menunjukkan bahwa, tanpa adanya variabel bebas yaitu; store layout $\left(\mathrm{X}_{1}\right)$, interior display $\left(\mathrm{X}_{2}\right)$ dan human $\left(\mathrm{X}_{3}\right)$, maka nilai shopping orientation (Y) sebesar 9,871.

Tabel 4. Uji Regresi

\begin{tabular}{lrrrrr}
\hline \multirow{2}{*}{ Model } & \multicolumn{2}{c}{ Unstandardized Coefficient } & \multirow{2}{*}{ T } & \multirow{2}{*}{ Sig. } & \multirow{2}{*}{ R Square } \\
\cline { 2 - 3 } & B & & & & \\
(Constant) & & 9.871 & 1.459 & .148 & .149 \\
Store Layout $\left(\mathrm{X}_{1}\right)$ & .365 & 2.860 & .005 & \\
Interior Display $\left(\mathrm{X}_{2}\right)$ & .221 & 2.568 & .012 & \\
Human $\left(\mathrm{X}_{3}\right)$ & .152 & .884 & .379 & \\
\hline
\end{tabular}

Sumber: Hasil Olah Data Penulis

2. Variabel store layout $\left(\mathrm{X}_{1}\right)$, memiliki koefisien regresi positif sebesar 0,365 dengan nilai signifikan $0,005<0,05$. Hasil perhitungan menunjukkan bahwa store layout berpengaruh positif terhadap variabel shopping orientation.

3. Variabel interior display $\left(\mathrm{X}_{2}\right)$, memiliki koefisien regresi positif 0,221 dengan nilai signifikan $0,012<0,05$. Hasil perhitungan menunjukkan bahwa interior display berpengaruh positif terhadap variabel shopping orientation.

4. Variabel human $\left(\mathrm{X}_{3}\right)$, memiliki koefisien regresi positif sebesar 0,152 dengan nilai signifikan $0,379>0,05$. Hasil perhitungan menunjukkan bahwa nilai $\beta$ menjadi tidak bermakna.

Uji F

Tabel 5. Uji F

\begin{tabular}{llcc}
\hline \multicolumn{2}{l}{ Model } & F & Sig. \\
\hline 1 & $\begin{array}{l}\text { Regression } \\
\text { Residual } \\
\text { Total }\end{array}$ & 5.616 & $.001^{\mathrm{a}}$ \\
& & \\
\hline \multicolumn{3}{l}{ Sumber: Hasil Olah Data Penulis }
\end{tabular}

Berdasarkan pada tabel 5 nilai signifikan adalah 0,001 $<0,05$ maka dapat dikatakan bahwa persamaan regresi yang digunakan sudah benar dan model dapat digunakan untuk uji penelitian.

\section{Uji t}

Berdasarkan pada tabel 4 di atas, maka diperoleh nilai signifikansi store layout $\left(\mathrm{X}_{1}\right) 0,005<$ 0,05 dan $t_{\text {hitung }}=2,860$ (Hipotesis diterima).

H1 diterima: store layout memiliki pengaruh signifikan terhadap shopping orientation.

Kemudian nilai signifikansi Interior display $\left(\mathrm{X}_{2}\right)$ 0,012 $<0,05$ dan $\mathrm{t}_{\mathrm{hitung}}=2,568$. (Hipotesis diterima). Hal ini didukung oleh Yuwono, (2017) yang mengungkapkan bahwa store layout merupakan variabel independen yang paling dominan berpengaruh terhadap customer shopping orientation pada Warkop Warung Masa Gitu di Bekasi.

$\mathrm{H} 2$ diterima: Interior display berpengaruh signifikan terhadap shopping orientation.

Hal ini didukung oleh Ma'ruf, (2006) yang menyatakan bahwa keinginan untuk melakukan pembelian dapat diciptakan melalui interior display yang menarik. Interior display adalah variabel 
yang menonjol secara signifikan. Andreani, Kristanti, \& Yapola, (2013) juga menyatakan bahwa interior display berpengaruh secara positif terhadap customer shopping orientation. Human $\left(\mathrm{X}_{3}\right)$ $0,379>0,05$ dan nilai $t_{\text {hitung }}=0,884$ (Hipotesis ditolak).

H3 ditolak: human tidak berpengaruh signifikan terhadap shopping orientation

\section{Uji Koefisien Korelasi (R) dan Koefisien Determinasi $\left(\mathbf{R}_{2}\right)$}

Merujuk pada tabel 6 dapat dilihat bahwa adjusted $R$ square bernilai 0,123 artinya kontribusi store layout, interior display dan human variables terhadap shopping orientation adalah sebesar $12,3 \%$ sedangkan $87,7 \%$ sisanya dipengaruhi oleh variabel-variabel lainnya yang tidak dimasukkan ke dalam penelitian ini.

\begin{tabular}{lcc} 
Tabel 6. Uji Koefisien Korelasi $(\mathbf{R})$ dan Koefisien Determinasi $\left(\mathbf{R}_{2}\right)$ \\
\hline \multicolumn{1}{c}{ Model } & $\boldsymbol{R}$ Square & Adjusted R Square \\
\hline (Constant) & & \\
Store Layout $\left(\mathrm{X}_{1}\right)$ & .149 & .123 \\
Interior Display $\left(\mathrm{X}_{2}\right)$ & & \\
Human Variables $\left(\mathrm{X}_{3}\right)$ & & \\
\hline
\end{tabular}

Sumber: Hasil Olah Data Penulis

\section{Uji Asumsi Klasik}

Berdasarkan analisis One-Sample Kolmogorov-Smirnov Test pada tabel 7 terlihat bahwa nilai Asymp. Sig. (2-tailed) sebesar 0,891>0,05. Oleh karena itu $\mathrm{H}_{\mathrm{o}}$ tidak dapat ditolak dan nilai residual berdistribusi secara normal.

Tabel 7. Uji Normalitas

One-Sample Kolmogorov-Smirnov Test

\begin{tabular}{llr}
\hline \multicolumn{2}{c}{ One-Sample Kolmogorov-Smirnov Test } \\
\hline $\mathrm{N}$ & & Unstandardized Residual \\
Normal & Mean & 100 \\
Parameters $^{a}$ & Std. Deviation & .0000000 \\
Most Extreme & Absolute & 3.84395048 \\
Differences & Positive & .058 \\
& Negative & .050 \\
Kolmogorov-Smirnov Z & -.058 \\
Asymp. Sig. (2-tailed) & .579 \\
\multicolumn{2}{c}{ Sumber: Hasil Olah Data Penulis }
\end{tabular}

Tabel 8. Uji Multikolinearitas

\begin{tabular}{llrr}
\hline \multirow{2}{*}{ Model } & \multicolumn{2}{c}{ Collinearity Statistics } \\
\cline { 2 - 4 } & Tolerance & VIF \\
\hline $1 \quad$ (Constant) & & \\
& Store Layout & .989 & 1.011 \\
& Interior Display & .987 & 1.013 \\
& Human Variables & .976 & 1.024 \\
\hline \multicolumn{3}{c}{ Sumber: Hasil Olah Data Penulis } \\
\end{tabular}


Uji multikolinearitas dapat dilihat pada tabel 8 yang diperoleh informasi bahwa ketiga variabel independen memiliki angka VIF store layout $\left(\mathrm{X}_{1}\right)$ 1,011, interior display $\left(\mathrm{X}_{2}\right)$ 1,013 dan Human $\left(\mathrm{X}_{3}\right)$ 1,024 yang memenuhi kriteria VIF < 10. Maka pada model regresi yang terbentuk tidak terjadi gejala multikolinearitas.

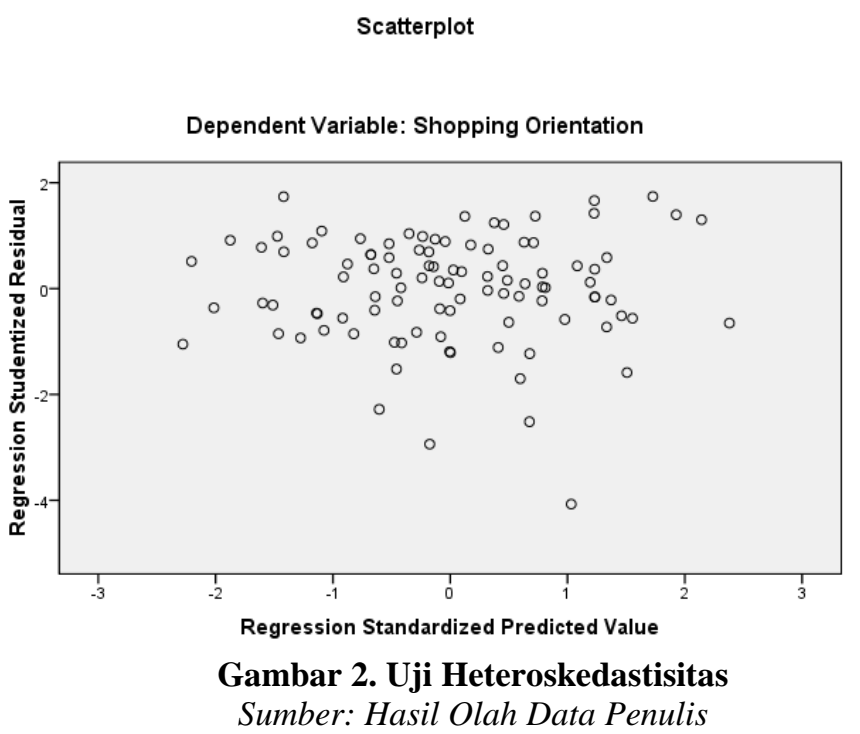

Uji Heteroskedastisitas berdasarkan pada gambar 2 dapat dilihat bahwa plot terpencar dan tidak membentuk pola tertentu. Jadi dapat dinyatakan bahwa tidak terjadi masalah homoskedastisitas atau persamaan regresi memenuhi asumsi Heteroskedastisitas.

Tabel 9. Uji Linearitas

\begin{tabular}{ccc}
\hline No & Variabel & Deviation from Linearity \\
\hline 1 & $\mathrm{Y}^{\mathrm{X}} \mathrm{X}_{1}$ & Sig. 0.548 \\
2 & $\mathrm{Y}_{2}-\mathrm{X}_{2}$ & Sig. 0.449 \\
3 & $\mathrm{Y}_{3}$ & Sig. 0.408 \\
\hline \multicolumn{3}{c}{ Sumber: Hasil Olah Data Penulis }
\end{tabular}

Berdasarkan pada tabel 9 di atas dapat terlihat adanya hubungan yang linear antara shopping orientation dengan store layout (Y-X $\left.\mathrm{X}_{1}\right)$ dengan Sig. 0,548, shopping orientation dengan interior Display $\left(\mathrm{Y}_{-} \mathrm{X}_{2}\right)$ dengan Sig. 0,449 dan shopping orientation dengan human ( $\mathrm{Y}^{\left.-\mathrm{X}_{3}\right)}$ dengan nilai Sig. 0,408, karena telah memenuhi kriteria Sig. $>0,05$.

\section{KESIMPULAN DAN SARAN}

\section{Kesimpulan}

Berdasarkan hasil penelitian dan pembahasan maka dapat ditarik kesimpulan sebagai bahwa 1) store layout memiliki pengaruh signifikan terhadap shopping orientation di Matahari Basko Grand Mall Padang, 2) interior display memiliki pengaruh signifikan terhadap shopping orientation di Matahari Basko Grand Mall Padang 3) human tidak berpengaruh signifikan terhadap shopping orientation di Matahari Basko Grand Mall Padang. 


\section{Implikasi Penelitian}

Penelitian ini dapat menambah wawasan dan ilmu pengetahuan di bidang manajemen pemasaran ritel, khususnya mengenai pemanfaatan store atmosphere untuk menunjang sebuah usaha sehingga membentuk shopping orientation. Penelitian ini juga dapat digunakan oleh manajer perusahaan/toko untuk meningkatkan kinerja store atmosphere dalam membentuk shopping orientation pada konsumennya. Store atmosphere khususnya store layout, interior display yang terkelola dengan baik akan membuat konsumen merasa senang dan nyaman ketika berada di dalam toko sehingga toko tersebut akan menjadi referensi yang utama ketika konsumen ingin berbelanja.

\section{Keterbatasan dan Saran}

Penelitian ini hanya meneliti tiga dimensi store atmosphere saja yaitu store layout, interior display dan human. Jumlah sampel dalam penelitian ini hanya menggunakan sampel minimum yaitu berfokus pada responden pelanggan Matahari Basko Grand Mall yang hanya berdomisili di Kota Padang dan hasil penelitian ini tidak bisa menggeneralisasikan perusahaan ritel yang ada di Kota Padang. Oleh sebab itu peneliti selanjutnya diharapkan mampu untuk meneliti keseluruhan dimensi dari store atmosphere untuk mendapatkan hasil penelitian yang lebih baik. 
Mardiah, A., Evanita, S., \& Septizola, W. (2021). Pengaruh Store Layout, Interior Display ....

\section{DAFTAR PUSTAKA}

Andreani, F., Kristanti, M., \& Yapola, A. (2013). Pengaruh Store Layout, Interior Display, Human Variable Terhadap Customer Shopping Orientation Di Restoran Dewandaru Surabaya. Jurnal Manajemen Dan Kewirausahaan. https://doi.org/10.9744/jmk.15.1.65-74

Baker, J., \& Wakefield, K. L. (2012). How consumer shopping orientation influences perceived crowding, excitement, and stress at the mall. Journal of the Academy of Marketing Science. https://doi.org/10.1007/s11747-011-0284-Z

Berman, B. R., \& Evans, J. R. (2014). Retail Management: A Strategic Approach (13th Edition). In Pearson. https://doi.org/10.1520/GTJ103256

Gunawan, Dodi; Mohamad, D. A. S. (2016). Pengaruh store layout, interior display serta human terhadap customer shopping orientation di Conato Cafe Roxy Square Jember. Artikel Ilmiah Mahasiswa 2016.

Kurniawan, Denny; dan Yohanes, S. K. (2013). Pengaruh Promosi dan Store Atmosphere Terhadap Impulse Buying dengan Shopping Emotion sebagai Variabel Intervening Studi Kasus di Matahari Department Store Cabang Supermall Surabaya. Jurnal Manajemen Pemasaran PETRA, 1(2), 18.

Levy, Michael; Weitz, B. A. (2012). Retailing Management. McGraw-Hill.

Ly, L. (2011). A Multi-method Exploration On Coffee Shop Atmospherics. Corcordia University.

Sekaran, Uma; \& Bougie, R. (2016). Research Methods for Business A Skill-Building Approach. https://doi.org/10.1017/CBO9781107415324.004

Solomon, Michael, R. (2011). Consumer Behaviour: buying having and being. Pearson Prentice Hall.

Sugiyono. (2018). Metode Penelitian Kuantitatif, Kualitatif, dan R\&D. Alfabeta.

Thamizhvanan, A. M. . X. (2013). Determinants of Customers' Online Purchase Intention: An Empirical Study in India. Journal of Indian Bussiness Research, Vol. 5(No. 1), 17-32.

Yuwono, R. E. (2017). Pengaruh Store Layout, Interior Display dan Human Variables terhadap Customer Shopping Orientation pada Warkop Warung Masa Gitu di Bekasi Utara. Pemasaran Dan Kewirausahaan, 1(3), 1-9. 